\title{
Randomized trial of achieving healthy lifestyles in psychiatric rehabilitation: the ACHIEVE trial
}

\author{
Sarah S Casagrande ${ }^{1}$, Gerald J Jerome ${ }^{2,3}$, Arlene T Dalcin², Faith B Dickerson ${ }^{4}$, Cheryl A Anderson ${ }^{1,5}$, \\ Lawrence J Appel ${ }^{1,2,5}$, Jeanne Charleston ${ }^{5}$, Rosa M Crum ${ }^{1,5,9,10}$, Deborah R Young ${ }^{9}$, Eliseo Guallar ${ }^{1,5}$, Kevin D Frick ${ }^{6}$, \\ Richard W Goldberg ${ }^{7,8}$, Meghan Oefinger ${ }^{2}$, Joseph Finkelstein ${ }^{1,2,6}$, Joseph V Gennusa III2, Oladapo Fred-Omojole ${ }^{2}$, \\ Leslie M Campbell2, Nae-Yuh Wang ${ }^{1,2}$, Gail L Daumit ${ }^{1,2,5,6,10,11^{*}}$
}

\begin{abstract}
Background: Overweight and obesity are highly prevalent among persons with serious mental illness. These conditions likely contribute to premature cardiovascular disease and a 20 to 30 percent shortened life expectancy in this vulnerable population. Persons with serious mental illness need effective, appropriately tailored behavioral interventions to achieve and maintain weight loss. Psychiatric rehabilitation day programs provide logical intervention settings because mental health consumers often attend regularly and exercise can take place on-site. This paper describes the Randomized Trial of Achieving Healthy Lifestyles in Psychiatric Rehabilitation (ACHIEVE). The goal of the study is to determine the effectiveness of a behavioral weight loss intervention among persons with serious mental illness that attend psychiatric rehabilitation programs. Participants randomized to the intervention arm of the study are hypothesized to have greater weight loss than the control group.
\end{abstract}

Methods/Design: A targeted 320 men and women with serious mental illness and overweight or obesity (body mass index $\geq 25.0 \mathrm{~kg} / \mathrm{m}^{2}$ ) will be recruited from 10 psychiatric rehabilitation programs across Maryland. The core design is a randomized, two-arm, parallel, multi-site clinical trial to compare the effectiveness of an 18-month behavioral weight loss intervention to usual care. Active intervention participants receive weight management sessions and physical activity classes on-site led by study interventionists. The intervention incorporates cognitive adaptations for persons with serious mental illness attending psychiatric rehabilitation programs. The initial intensive intervention period is six months, followed by a twelve-month maintenance period in which trained rehabilitation program staff assume responsibility for delivering parts of the intervention. Primary outcomes are weight loss at six and 18 months.

Discussion: Evidence-based approaches to the high burden of obesity and cardiovascular disease risk in person with serious mental illness are urgently needed. The ACHIEVE Trial is tailored to persons with serious mental illness in community settings. This multi-site randomized clinical trial will provide a rigorous evaluation of a practical behavioral intervention designed to accomplish and sustain weight loss in persons with serious mental illness.

Trial Registration: Clinical Trials.gov NCT00902694

\section{Background}

The prevalence of overweight and obesity has significantly increased over the past several decades with roughly $34 \%$ of U.S. adults currently being obese [1,2]. In persons with serious mental illness (e.g., schizophrenia,

\footnotetext{
* Correspondence: gdaumit@jhmi.edu

'Welch Center for Prevention, Epidemiology, and Clinical Research, Johns

Hopkins University, Baltimore, Maryland, USA

Full list of author information is available at the end of the article
}

bipolar disorder), overweight and obesity are at epidemic levels that are higher than in the overall U.S. population [3-5]. Obesity significantly increases the risk of morbidity and mortality from cardiovascular disease mainly through the effects of obesity on hypertension, hyperlipidemia and diabetes mellitus [6,7]. Furthermore, many classes of psychotropic drugs are associated with weight gain. [3,8,9]. Given the long-term needs of most patients with serious mental illness to continue psychotropic medications,

\section{Biomed Central}


interventions to reduce obesity and cardiovascular risk are urgently needed.

National guidelines for weight loss emphasize a multifaceted approach to include reduced energy intake, improved dietary patterns and increased physical activity [10-13]. Randomized controlled behavioral weight loss intervention trials showing efficacy for weight loss in the general population have systematically excluded individuals with chronic mental illness from participating [14-19]. In addition, behavioral lifestyle interventions in persons with serious mental illness pose several challenges since these individuals may have competing demands on a daily basis. Person with serious mental illness are often dealing with active mental health symptoms, housing issues, substance abuse or other social issues that may take precedence over behavioral change for weight loss. Furthermore, the high prevalence of cognitive deficits in this population can impede individuals from successfully performing activities of daily living [20]. Thus, traditional behavioral interventions that have been shown to be effective in populations without mental illness should be tailored to meet the specific needs of persons with serious mental illness [14].

There have been few behavioral interventions that have targeted weight loss in persons with serious mental illness. Most previous studies have applied strategies similar to those used in trials for the general population and have focused exclusively on dietary intake with a few incorporating some physical activity component. Furthermore, the interventions in this population have been small ( $<60$ participants), without a control comparison group and have used various methods to induce behavior change [21-28]. Nevertheless, the literature indicates that selected persons with serious mental illness can benefit from short-term behavioral weight loss interventions [17]. Given the health benefits of exercise and healthy dietary patterns, randomized controlled trials of comprehensive weight loss interventions (dietary and physical activity components) are needed among persons with serious mental illness.

This protocol describes a randomized, controlled trial of a comprehensive behavioral weight loss and weight maintenance program among persons with serious mental illness that attend psychiatric rehabilitation day programs across Maryland. Psychiatric rehabilitation programs (PRP) are outpatient facilities where persons with serious mental illness attend up to several days a week and receive vocational and other services. Psychiatric rehabilitation programs may be opportune and efficient settings for testing, implementing and disseminating interventions. Rehabilitation programs have classroom and communal space suitable for group weight management and exercise sessions. The potential sustainability of a weight loss intervention at psychiatric rehabilitation programs may be more feasible than in other types of mental health settings because consumers regularly attend and the centers already offer other types of classes. In addition, most rehabilitation programs serve persons with a range of serious mental illness diagnoses, including schizophrenia; thus, interventions targeted to these settings could generalize to broad populations with serious mental illness.

\section{Methods}

\section{Study Design Summary}

The core design is a randomized, two-arm, parallel, multi-site clinical trial. Inclusion/exclusion criteria were chosen to enroll a population with chronic mental illness who are overweight or obese and who may safely participate in a weight loss intervention including moderate intensity exercise. Interested mental health consumers are being screened for eligibility at 10 psychiatric rehabilitation centers across Maryland. Three hundred and twenty adult participants completing screening are targeted for enrollment and randomization to the ACHIEVE (Achieving Healthy Lifestyles in Psychiatric Rehabilitation) intervention or usual care. Intervention participants receive group and individual weight management sessions and group physical activity classes. In the initial 6-month intervention phase, study interventionists lead the sessions and also train designated rehabilitation program staff. A 12-month maintenance intervention phase follows in which interventionists continue leading some sessions and trained rehabilitation staff assume responsibility for delivering part of the intervention. Interventionists also provide education to rehabilitation program kitchen staff to increase options for healthy meals served on-site. Follow-up data collection occurs at 6,12 , and 18 months from baseline. The study was approved by the Johns Hopkins Institutional Review Board (protocol number NA00015231).

\section{Specific Aims \\ Primary Aim}

Determine the effect of the ACHIEVE intervention on weight loss at 6 and 18 months. The hypothesis is that the ACHIEVE intervention group will have greater weight loss than the control group.

\section{Secondary Aims}

Determine the effect of the ACHIEVE intervention on the following outcomes at 6 and 18 months: physical fitness by submaximal bicycle ergometer; waist circumference; blood pressure; lipids; Framingham cardiovascular risk score; health status with SF-12 and depression with CES-D. The hypothesis is that the ACHIEVE intervention group will have greater improvement of these outcomes compared to the control group. In addition, costs per participant will be assessed and a cost effectiveness analysis will be performed. 


\section{Study sites and population}

The study sites will include 10 community psychiatric rehabilitation programs across urban and suburban Maryland. Each location shares certain features: (1) adult psychiatric rehabilitation day program with consumers attending regularly at least 3 days a week; (2) space for on-site physical activity classes; and (3) meals served to consumers. The trial is enrolling men and women, age 18 and older who are overweight (body mass index $\geq 25.0 \mathrm{~kg} / \mathrm{m}^{2}$ ) or obese and attend the psychiatric rehabilitation programs. By definition of their psychiatric rehabilitation attendance, these participants have a serious mental illness diagnosis. Persons with serious mental illness that receive care from rehabilitation programs' on-site mental health clinics are also eligible for recruitment. The inclusion and exclusion criteria for the trial are listed below.

\section{Inclusion criteria}

- Age 18 and older;

- Overweight, defined by Body Mass Index at least $25.0 \mathrm{~kg} / \mathrm{m}^{2}$;

- Able and willing to give informed consent and participate in the intervention;

- On the same psychiatric medications within the 30 days before baseline weight (dose changes allowed;)

- Able to attend at least 2 intervention sessions per week (one weight management and one physical activity session) during initial 6-month phase;

\section{Exclusion criteria}

- Contraindication to weight loss

- Receiving active cancer treatment (radiation/ chemotherapy)

- Liver failure

- History of anorexia nervosa;

- Cardiovascular event (unstable angina, myocardial infarction) within previous 6 months;

- Prior or planned bariatric surgery;

Use of prescription weight loss medication or overthe-counter orlistat within 3 months

if participant does not agree to stop taking it;

- Twenty pound or greater weight loss in 3 months prior to baseline, as documented by staff measurement;

- Inability to walk to participate in exercise class;

- Pregnant or planning a pregnancy during study period. Nursing mothers would need approval from physician;

- Alcohol or substance use disorder either: 1) active and determined to be incompatible with participation in the intervention through discussion with program staff; or 2) new abstinence from alcohol or substance use disorder in past 30 days;
- Planning to leave rehabilitation center within 6 months or move out of geographic area within 18 months;

- Investigator judgment (e.g., for concerns over safety, adherence or follow-up);

- Weight greater than 400 pounds.

\section{Recruitment Strategies}

Most recruitment activities occur on-site at the psychiatric rehabilitation centers and affiliated psychiatric clinics. The primary means of recruitment is direct communication with consumers. Regular mental health consumer meetings at the rehabilitation programs provide opportunities for study staff to present the study. During presentations, study staff often show an informational video and may incorporate an exercise class demonstration. Posters are displayed and fliers and brochures are distributed. In addition, study staff make presentations to rehabilitation program staff and outpatient mental health clinic staff. Rehabilitation program staff and outpatient clinic staff may mention the study to their clients. Potential participants also are identified by working with rehabilitation staff and reviewing together the list of rehabilitation program attendees, using a HIPAA waiver. Study staff are available on-site at the rehabilitation programs to discuss the study during the times when consumers attend. Potential participants are also given a phone number and a postcard to mail back to reach study staff to indicate their interest.

To track recruitment, a roster of consumers attending the center is provided by each rehabilitation program. These rosters assist in defining and counting the number of consumers contacted and enable the characterization of enrollees and non-enrollees.

\section{Data Collection and Measurements}

Before formal screening for the trial begins, oral consent from rehabilitation center attendees is obtained and their weight and height at study baseline is measured for calculation of body mass index; weight will be measured again at 6 and 18-month follow up data collection points. Measuring weight of all consumers at the day program, regardless of their interest in joining the weight loss intervention study, allows for an understanding of: (1) the natural history of weight gain in this population without intervention and (2) how the environmental component of the intervention (i.e., increasing options for healthy meals on-site) may affect weight at the centers in a pre/post fashion. The goal will be to measure height and weight for as many attendees as possible.

For the formal trial, all participants provide written informed consent using procedures reviewed and approved by Johns Hopkins Institutional Review Boards 
(IRB). A two-stage consent process is used with the first consent obtained to conduct screening procedures and a second consent obtained after baseline data collection and prior to randomization. An evaluation of ability to give consent is also administered for each participant before screening consent which includes answering questions about the goal of the study, what they will be asked to do, and what risks may be involved if they join the study. If a participant is deemed not able to give consent, he/she may not join the study.

Participant eligibility is determined by the completion of several screening measures. The Rose Angina Questionnaire and a checklist of medical conditions are implemented to determine health status for a moderate intensity exercise program [29]. If potential participants have a positive Rose Questionnaire, a prior history of cardiovascular disease or have diabetes mellitus, they require an approval letter from their primary care physician in order to enroll in the study. In addition, primary care physicians for all participants are contacted about the study to ensure there are no contraindications to weight loss or participation in moderate intensity physical activity. Alcohol and substance abuse are assessed with the Addiction Severity Index-Lite [30]; medications are reviewed; and plans to remain at the rehabilitation center during the duration of the study to participate in the trial are discussed with the consumer.

Data collection visits occur on-site at psychiatric rehabilitation centers and are conducted by trained data collectors certified in study measures. Measurements are conducted using standardized operating procedures and quality control methods. Table 1 summarizes the data collection measures and schedule. Follow-up measures are collected at 6, 12, and 18 months after baseline.

\section{Randomization and Blinding}

After baseline data collection and before the intervention begins, participants meet with study staff and the intervention arms of the study are described in detail. The study coordinator confirms that the participant meets eligibility criteria, and that all required baseline data have been collected. Participants interested in enrollment are consented individually and randomized to either the intervention or the control group. The study coordinator ascertains and communicates treatment assignments to participants [31]. Randomization is stratified by gender and site using blocks of sizes 2 and 4 in random order to create the randomization sequence for each stratum.

Due to the nature of the intervention, both participants and interventionists will be aware of the assignment. The following mechanisms are in place for data collection staff to be masked to treatment assignment:
1) designating and tracking unmasked study staff; 2) excluding data collection staff from any part of intervention delivery; 3 ) performing outcome assessments in separate rooms than the intervention; and 4) reminding participants not to share their group assignment. Until the trial end, investigators, staff and participants are masked to outcome data with the exception of the trial statistician and data analyst. In addition, the primary outcome variable, weight, is subject to very little measurement bias [32].

\section{Intervention}

The ACHIEVE intervention incorporates concepts from social cognitive theory, behavioral self-management and the relapse prevention model [33-36]. The theoretical base of the ACHIEVE Trial fits well within the psychiatric rehabilitation framework which emphasizes tenets of intrinsic skills building and environmental supports $[37,38]$. Motivational interviewing provides an important framework for helping participants problem solve and set goals for weight loss.

The ACHIEVE intervention operationalizes these models by providing frequent and extended contacts, opportunities for group interactions and social support, goal setting and self-negotiation, problem solving, and examples of new behavioral options. The intervention was developed from a comprehensive lifestyle intervention tested in the NHLBI sponsored PREMIER Trial (A Trial of Lifestyle Interventions for Blood Pressure Control), which has proven efficacious for weight loss by incorporating dietary and physical activity components $[16,19,39]$. To the PREMIER foundation of individual and group counseling sessions, on-site physical activity sessions were added to take advantage of the psychiatric rehabilitation environment as an opportunity for both skills modeling and attaining most of the weekly recommended physical activity. To further tailor the intervention, the neurocognitive deficits in working memory, verbal memory and executive function that are common in persons with serious mental illness were addressed $[40,41]$. Successful didactic interventions in schizophrenia emphasize learning a few, specific and narrow skills repeatedly, breaking material into small units, learning aides to reduce requirements on memory and attention, repetition of content, and rehearsing behavioral skills [42]. One successful approach for coping with cognitive deficits is the use of compensatory environmental strategies, which are adaptations in the environment designed to bypass neurocognitive impairments and improve adaptive functioning [43]; examples include signs, labels, and devices designed to cue and sequence appropriate behaviors and structure [44]. All aspects of the ACHIEVE intervention were tailored to meet the 
Table 1 ACHIEVE Trial Data Collection Schedule

Baseline $6 \mathrm{mo} 12 \mathrm{mo} 18 \mathrm{mo}$

\section{For all rehabilitation enrollees:}

\begin{tabular}{lll}
\hline Age, gender, race & $X$ & \\
\hline Height & $X$ & \\
\hline Weight & $X \quad X \quad x$ \\
\hline
\end{tabular}

\section{For trial participants:} Medical history

\begin{tabular}{|c|c|c|c|c|}
\hline Rose Angina Questionnaire [29] & $x$ & $x$ & $x$ & $x$ \\
\hline Medical conditions & $x$ & $x$ & & $x$ \\
\hline Substance Use (Addiction Severity Index-Lite)[30] & $x$ & & & \\
\hline Mental health diagnoses (chart review) & $x$ & & & \\
\hline Medications & $x$ & $x$ & $x$ & $x$ \\
\hline \multicolumn{5}{|l|}{ Physical measures } \\
\hline Height & $x$ & & & \\
\hline Weight & $x$ & $x$ & $x$ & $x$ \\
\hline Submaximal bicycle ergometer & $x$ & $x$ & & $x$ \\
\hline Waist circumference & $x$ & $x$ & & $x$ \\
\hline Blood pressure- 3 measures at each of 3 visits, 1 week apart & $x$ & $x$ & & $x$ \\
\hline \multicolumn{5}{|l|}{ Fasting serum measures } \\
\hline Glucose & $x$ & $x$ & & $x$ \\
\hline Insulin & $x$ & $x$ & & $x$ \\
\hline Lipids (total cholesterol, LDL, HDL, triglycerides) & $x$ & $x$ & & $x$ \\
\hline C-reactive protein & $x$ & $x$ & & $x$ \\
\hline \multicolumn{5}{|l|}{ Health behaviors } \\
\hline Block Diet Screeners $[57,58]$ & $x$ & $x$ & & $x$ \\
\hline Direct observation of diet at rehabilitation centers & $x$ & $x$ & & $x$ \\
\hline Food preparation and shopping habits & $x$ & $x$ & & $x$ \\
\hline Physical Activity (International Physical Activity Questionnaire) [59] & $x$ & $x$ & & $x$ \\
\hline Tobacco smoking & $x$ & $x$ & & $x$ \\
\hline \multicolumn{5}{|l|}{ Mental health symptoms } \\
\hline Behavior and Symptom Identification Scale-24 [60] & $x$ & $x$ & & $x$ \\
\hline Center for Epidemiologic Studies Depression Scale [61] & $x$ & $x$ & & $x$ \\
\hline \multicolumn{5}{|l|}{ Health status-SF-12 [62] } \\
\hline Quality of life measures & $x$ & $x$ & & $x$ \\
\hline \multicolumn{5}{|l|}{ Euroqol EQ-D [63] } \\
\hline \multicolumn{5}{|l|}{ Impact of Weight on Quality of Life-Lite [64] } \\
\hline \multicolumn{5}{|l|}{ Social support measures } \\
\hline \multicolumn{5}{|l|}{ MOS Social Support Survey [65] } \\
\hline \multicolumn{5}{|l|}{ Social Support and Eating/Exercise (adapted) [66] } \\
\hline \multicolumn{5}{|l|}{ Self-efficacy measures } \\
\hline \multicolumn{5}{|l|}{ General Self Efficacy Scale [67] } \\
\hline Weight Efficacy Lifestyle Questionnaire [68] & & & & \\
\hline Physical Activity Barriers Self-Efficacy Scale [69] & & & & \\
\hline
\end{tabular}

Other measures (binge eating, weight loss history, neighborhood characteristics, mobility, sleep quality) [70-73]

Safety measures

$x \quad x \quad x$




\begin{tabular}{|c|c|}
\hline Self-monitoring & $\begin{array}{l}\text {-Tracker: participants mark fruits/vegetables, sugar drinks, junk food, smart portions, smart snacks and exercise. } \\
\text { Detailed food and calorie log not required so complexity of recording is simplified. } \\
\text {-Weigh-in one time per week during the intensive phase, and once per month during the maintenance phase. } \\
\text { Frequent weigh-ins provide opportunity for reinforcement and repetition. }\end{array}$ \\
\hline $\begin{array}{l}\text { Group weight-management } \\
\text { sessions }\end{array}$ & $\begin{array}{l}\text {-Highly structured, emphasis on behavioral rehearsal. } \\
\text {-Material taught in small content units. Frequent meetings ( } 1 \text { session per week during the intensive phase, } 1 \text { session } \\
\text { per month during the maintenance phase) allow repetition of concepts. } \\
\text {-Program materials are written at } 5^{\text {th }}-8^{\text {th }} \text { grade reading level. } \\
\text { - Hands-on activities emphasized. Taste testing, label reading, portion measuring. } \\
\text { - Role-playing emphasized. Practicing saying no to junk food, or choosing smarter portions at a birthday party. } \\
\text { Increases self-efficacy to adhere to healthier eating habits. } \\
\text {-Worksheets review topic of the week. }\end{array}$ \\
\hline Individual sessions & $\begin{array}{l}\text {-Allow for individualized cognitive tailoring as needed. } \\
\text {-Opportunity to emphasize an individualized high impact behavior based upon the concepts learned in groups. }\end{array}$ \\
\hline Physical activity classes & $\begin{array}{l}\text {-Provide opportunity for modeling and building physical activity skills in supportive setting to increase cardiovascular } \\
\text { fitness and exercise self efficacy }\end{array}$ \\
\hline Environmental prompts & $\begin{array}{l}\text {-Refrigerator magnets, preprinted grocery lists, watches, water bottle, measuring cups, lunch bag as reminders to be } \\
\text { used at home. }\end{array}$ \\
\hline Reinforcements & -Participation is rewarded with varying levels of gifts relative to the number of classes attended. \\
\hline
\end{tabular}

specific needs of a psychiatric rehabilitation population. Table 2 outlines the cognitive adaptations in the intervention.

The main intervention goals of ACHIEVE include: (1) reducing caloric intake by avoiding sugar drinks and "junk food," (2) eating 5 fruits and vegetables a day, (3) choosing smart portions and snacks, and (4) increasing caloric expenditure through participation in 3 moderate intensity aerobic exercise sessions per week at the psychiatric rehabilitation program [10].

Table 3 reflects the ACHIEVE intervention characteristics for participants randomized to the intervention group. In the first individual session, the interventionist begins a partnership with the participant and assesses his/her readiness to change and understanding nutritional principles. Behavior goals are set and in subsequent sessions the interventionist uses feedback and motivational interviewing techniques to assess the participant's current progress and to help move towards the next goal. These sessions allow the interventionist to tailor the intervention to individual needs.

Group weight-management classes occur three times per month during the intensive phase of the intervention and each month the classes are focused on one main topic, such as increasing fruit and vegetable consumption. The sessions begin with a discussion to support and review the concepts discussed and practiced since the prior session. A portion of the weekly session is devoted to didactic information about healthy eating or physical activity education, which is supported by food models and posters, a self-monitoring worksheet, hands-on activities related to the monthly topic, or food tastings. Participants set individual behavioral goals based on the material presented that week.
Group physical activity sessions are held three days per week at the rehabilitation center (e.g., in a multipurpose area) and led by a trained exercise leader from the study staff. A progressive exercise program starts at a level appropriate for sedentary adults: 10-minute warmup; 10 minutes of moderate intensity physical activity and 5-minute cool down [45]. The exercise duration gradually increases each week until participants are completing 40 minutes of moderate intensity physical activity and 10 minutes of warm-up and cool-down. Participants are encouraged to incorporate daily physical activity outside of the group exercise class and may set goals that reflect this effort.

In addition to the organized sessions, participants meet with the intervention staff monthly for an individual weight loss counseling session. This brief activity provides immediate feedback on weight loss progress. If participants lose weight, they are asked what worked for them. If they gain weight, staff work to problem-solve and assist in working towards a behavioral goal or setting a more realistic goal.

Self-monitoring and positive reinforcement are important aspects of successful weight loss trials. Participants are asked to fill out a "Tracker" as a self-monitoring tool outside of group sessions. Each tracker is used for one week; participants record the number of servings of fruits and vegetables, and respond yes or no to: exercising for 30 minutes; drinking sugar drinks; eating junk food; smart portions or smart snacks. The Tracker provides a behavioral cue to participants. An incentive program rewards participation in class and individual sessions with choices of varying priced items (e.g., gym suit, store gift card) after a specified number of stickers have been earned. In order to earn a sticker in exercise 
Table 3 Description of ACHIEVE Intervention

\begin{tabular}{|c|c|c|}
\hline \multicolumn{3}{|c|}{ Initial Intervention (Months 1 through 6) } \\
\hline Type of contacts & \multicolumn{2}{|c|}{ Frequency } \\
\hline Group weight-management class led by interventionist ( $45 \mathrm{~min}$.) & \multicolumn{2}{|c|}{$\begin{array}{l}\text { Once per week } \\
3 \text { of } 4 \text { weeks }\end{array}$} \\
\hline Individual visit with interventionist (15-20 min.) & \multicolumn{2}{|c|}{ Once per month } \\
\hline Group physical activity class led by exercise leader/interventionist (50 min.) & \multicolumn{2}{|c|}{ Three times per week } \\
\hline Weigh-in during weight management group and individual visit (2 min.) & \multicolumn{2}{|c|}{ Once per week } \\
\hline \multicolumn{3}{|c|}{ Maintenance Intervention (Months 7 through 12) } \\
\hline \multirow[t]{2}{*}{ Type of contacts } & \multicolumn{2}{|c|}{ Frequency } \\
\hline & Months 7 through 12 & Months 13 through 18 \\
\hline $\begin{array}{l}\text { Group weight management class } \\
\text { Overall frequency }\end{array}$ & Once per month & Once per month \\
\hline Led by interventionist & Monthly & Monthly \\
\hline Individual visit with interventionist & Every 4 weeks & Every 4 weeks \\
\hline $\begin{array}{l}\text { Group physical activity class } \\
\text { Overall frequency }\end{array}$ & Three times per week & Three times per week \\
\hline Led by exercise leader/interventionist & Twice per week & Once per week \\
\hline Monitored by rehab program staff & Once per week & Twice per week \\
\hline $\begin{array}{l}\text { Weigh-in } \\
\text { Overall frequency }\end{array}$ & Twice per month & Twice per month \\
\hline With intervention staff & Twice per month & Twice per month \\
\hline \multicolumn{3}{|c|}{ Core Components } \\
\hline Self-monitoring & \multicolumn{2}{|c|}{ Weigh-ins, Tracker food/exercise log } \\
\hline Goal setting, feedback, problem solving & \multicolumn{2}{|c|}{$\begin{array}{l}\text { Motivational interviewing and support at group and individual } \\
\text { sessions }\end{array}$} \\
\hline Social support & \multicolumn{2}{|c|}{$\begin{array}{l}\text { Group and individual weight management sessions, group physical } \\
\text { activity sessions }\end{array}$} \\
\hline Skills training & \multicolumn{2}{|c|}{$\begin{array}{l}\text { Weight management group sessions, physical activity sessions, } \\
\text { individual sessions }\end{array}$} \\
\hline Environmental supports & \multicolumn{2}{|c|}{$\begin{array}{l}\text { Physical activity sessions, Staff education in health food choices on- } \\
\text { site }\end{array}$} \\
\hline Environmental contingencies/reinforcements & \multicolumn{2}{|c|}{ incentive items for attendance, participation and specific behaviors } \\
\hline
\end{tabular}

class the participant must remain standing and engaged in class from the first minute of warm up through the last minute of cool down. For weight management group and individual visits, participants earn a sticker for being present in class throughout the entire duration of the session time.

For the maintenance intervention period, rehabilitation center staff assumes the responsibility for much of the exercise portion of the intervention in a stepped process over two 6-month phases. Designated rehabilitation center employees are trained by intervention study staff and provided with exercise videos made by the study team in an effort to mimic the instructor led exercise class as much as possible. The rehabilitation staff take responsibility for encouraging attendance and participation, starting the video, overseeing the safety of the class, and recording attendance data. Intervention study staff are available for consultation as needed to offer more support during this phase. This transition occurs in order to facilitate the rehabilitation center's ownership of the program, with the goal of increasing the likelihood that the center will continue to offer components of the intervention after the study is complete.

\section{Intervention Delivery}

ACHIEVE interventionists are skilled facilitators with experience in behavior change and group and individual-level counseling. Interventionists have a skill level that would be typical for a community health educator with a bachelor's degree; exercise leaders have at least one year of experience in leading an exercise class and/ or are a certified exercise instructor. Intervention staff are trained to deliver any or all components of the intervention in order to maximize the resources of this multi-site trial. Manualized procedures and standardized materials are used to ensure consistency of the 
intervention including standardized formats for the group exercise classes. Staff members are regularly observed as part of ongoing staff training and fidelity assurance.

Psychiatric rehabilitation program leadership and staff at each site support the intervention and are involved in the study on multiple levels. Program leadership from each site work with the study team so that intervention classes fit into the overall center schedule, and collaborate on participants' individual rehabilitation plans. Each site designates at least one employee to become trained to conduct group physical activity classes using an exercise video.

Resources included in measuring the costs of the intervention delivery include the number of staff, and the duration of each activity. For each study site, staff record one week of data at intervention months 2, 3, 5, 6, 12, 15 and 18. Staff time includes time with participants for intervention sessions, time spent preparing for sessions, training and intervention-related meetings. All research related activities are excluded from the cost analysis.

\section{Control Group}

Participants in the control group receive standard nutrition and physical activity written information at baseline. Health classes are held quarterly for control participants with content unrelated to weight loss (e.g., cancer screening, oral health).

\section{Environmental Nutrition Intervention}

In order to support intervention group participants' ability to select healthy foods, interventionists provide consulting services to rehabilitation program kitchen staff. The consultation sessions help kitchen staff identify healthier food choices for meals served on-site within site budget and regulatory constraints (e.g., federal food guidelines). Interventionists work with rehabilitation staff to identify goals and then offer options to improve food choices such reducing high sugar foods, working on appropriate portion sizes and modifying vending machine offerings. Rehabilitation staff choose goals and which options they will incorporate.

A random sample of menus at baseline, 6 months, and 18 months are collected and evaluated for nutritional content using ESHA software (The Food Processor, 2009, Salem, OR) [46].

\section{Data Analysis}

Randomly assigned intervention group (i.e., behavioral intervention or control) is the main independent variable for intent-to-treat analysis [47]. The co-primary outcomes are weight loss at 6 and 18 months. To evaluate the efficacy of the intervention for each of these outcomes, generalized estimating equations are used [48]. These models account for the longitudinal nature of the trial and incorporate baseline, and 6, 12 and 18-month measurements and will account for study site and other baseline characteristics found not to be balanced by randomization. For secondary outcomes that are categorical, logistic regression GEE models are used according to the same principles outlined above for continuous outcomes.

In addition to the analyses that preserve the intention to treat principle, analyses on subgroups defined postrandomization are exploratory. These include analyses in participants who attended the majority of weight management and exercise intervention sessions.

Although second generation antipsychotics and other psychotropic medications can induce substantial weight gain $[3,9]$, we expect that both study groups will be equivalent in their distribution of these medication due to the process of randomization. Several analytical approaches are planned to address three main potential effects of antipsychotic and other concomitant medication on study outcomes; these include: (1) imbalances in medication use between the intervention and control groups, despite randomization procedures, (2) variation in intervention efficacy by medication or medication class, and (3) changes in drug use after randomization.

The analytic approach to handle missing data will be anchored on the assumption that data is missing at random (MAR), where the probability of missing can depend on all observed information such as measured weights and covariates but does not depend on variables that are not recorded. The analysis model will include parameters for visit specific means for each treatment group, baseline covariates associated with study retention, and use an unstructured covariance structure. Missing at random is almost never strictly correct, but careful modeling should make the missing data process as close to MAR as possible. Primary analyses will be conducted under the assumption of MAR; sensitivity analyses will be based on sensible "missing not at random" scenarios to evaluate the robustness of the inferences under the MAR assumption.

For the environmental nutrition intervention, the menus are collected at each data collection time point and analyzed for nutrients using ESHA software. The mean number of calories, macronutrients, and micronutrients at each site are determined and $t$-tests are used to determine significant differences at each time point. Given the expected variability between sites in making changes to menus, differences in menu changes will be assessed within each site and then overall.

To support the long-term goal to integrate the ACHIEVE program into psychiatric rehabilitation centers, a cost analysis is planned. The primary analysis 
assesses the direct cost per participant of intervention implementation from the perspective of a future payer (e.g., Medicaid). A second analysis assesses costs from the societal perspective projecting cardiovascular risk factor changes 10 years into the future.

\section{Sample size and power}

The main objective of this trial is to detect weight loss having public health significance. Previous work has indicated that 4-5 pounds of weight loss should reduce systolic blood pressure by $\sim 3 \mathrm{mmHg}$, which has been estimated to reduce stroke mortality by $6-8 \%$; cardiovascular heart disease mortality by $4-5 \%$; and to reduce risk of incident hypertension by $20 \%$ [18,49]. A Monte Carlo simulation study was used to assess the power to detect a clinically meaningful effect on weight loss at months 6 and 18 under a range of conservative assumptions about the effect size, standard deviation, and follow-up with potentially clustered sites [50]. It was assumed that a 4.5 lb difference in weight at 18 months between intervention and control groups would be observed and that the difference at 6 months would be larger. For power calculations, we assumed a standard deviation of change in weight of $12 \mathrm{lbs}$ and that follow-up would be $80 \%$ complete. Under these assumptions, for two-sided 0.05-level tests of the null hypothesis, the study should provide approximately $86 \%$ power for detecting a difference of $4.5 \mathrm{lbs}$ with $\mathrm{SD}=12 \mathrm{lbs}$. In addition, the study will have the same power to detect the a similar effect size with a smaller sample size if we achieve a higher follow-up rate.

\section{Discussion}

Despite successful behavioral weight loss interventions in the general population, few randomized controlled trials of comprehensive behavioral weight loss interventions among persons with serious mental illness have been performed [51]. Given the high prevalence of obesity and cardiovascular risk factors, effective weight loss programs are needed in this vulnerable population. The ACHIEVE investigators led a previous pilot weight loss study ( $\mathrm{n}=$ 52) in two psychiatric rehabilitation programs and demonstrated preliminary success with high levels of recruitment, retention and pre/post weight loss of 4.8 pounds [52]. The ACHIEVE Trial will definitively test the effectiveness of this innovative, practical intervention to realize and sustain weight loss in overweight and obese persons with serious mental illness. If successful, the intervention will be a model program that should provide important health benefits by reducing cardiovascular disease risk for persons with serious mental illness, and with appropriate resources, could be disseminated widely.

This study compares the effectiveness of a multifaceted weight loss intervention to a standard care group among persons who often have cognitive impairments and other comorbidities. Behavioral weight loss trials have shown efficacy for weight loss in other populations. For example, the ACHIEVE intervention was modeled after the PREMIER Trial, a comprehensive lifestyle intervention that incorporated education and counseling for diet and physical activity; the trial was proven effective for weight loss in the general population [39]. The Trial of Nonpharmacologic Intervention in the Elderly (TONE) study demonstrated significant weight loss (3.5$4.5 \mathrm{~kg}$ average reduction) among adults age $60-80$ years over a 30-month follow-up period [53]. Similarly, initial 1 -year results from the Look AHEAD (Action for Health in Diabetes) trial have shown that older adults $(>65$ years) attend more lifestyle intervention sessions and participate in more physical activity than their younger counterparts [54]. At the end of a 6-month follow-up period, participants in The Weight Loss Maintenance trial demonstrated significant weight loss across racial and gender groups; weight loss was greatest among non-African American men and least among African American women [55].

Although there have been few behavioral weight loss intervention trials among persons with serious mental illness, previous work suggests that short-term weight loss can be achieved in this population $[51,56]$. The magnitude of weight change in ACHIEVE and other trials for persons with serious mental illness could be lower than seen in other studies and populations. If true, this may be due in part to participants having difficulty incorporating targeted behaviors from weight management sessions or lacking resources to buy lowercalorie foods. Other barriers to weight loss may include persistent mental health symptoms and frequent hospitalizations. However, the ACHIEVE Trial is unique in that interventionists provide frequent and extended contacts at locations participants regularly attend. In contrast, previous lifestyle interventions in populations without mental illness often have less frequent in-person interaction and require participants to go to other locations for intervention groups and data collection. The frequent contacts in a familiar setting in ACHIEVE may help overcome barriers from cognitive limitations and/ or mental health symptoms and subsequently foster significant weight loss. The multiple components of the intervention are designed to include a variety of methods to induce behavior change through repetitive and on-going activities (e.g., group and individual sessions, rewards, food models, daily record trackers).

The ACHIEVE Trial is one of the first weight loss trials that incorporates tailored weight management sessions and on-site exercise classes to persons with serious mental illness. This multi-site study will include a diversity of racial/ethnic groups, suburban and urban areas 
across Maryland, younger and older adults, and persons with varying severity and types of psychiatric disease. Thus, the results should be applicable to a wide range of persons with serious mental illness.

One challenge of the ACHIEVE Trial is the extensive support and buy-in from staff at the psychiatric rehabilitation centers required for success. ACHIEVE interventionists and data collectors need the center's physical space and other resources such as time to consult with staff in order to implement the intervention and collect data. Even with enthusiasm from psychiatric rehabilitation programs, intervention implementation may still be challenging because of certain program constraints. In the current funding environment, many mental health programs are under significant financial stress and have high staff turnover.

If the ACHIEVE intervention proves effective, there will be strong justification for mechanisms to sustain the program at current sites and disseminate it to other centers. Resource data collected during the trial will inform future costs of continuing the intervention. Practical considerations for intervention sustainability and dissemination are complex and include how cardiovascular disease prevention fits into centers' priorities and what funding the rehabilitation programs would have to conduct the intervention. Centers likely would need dedicated resources or reimbursement mechanisms to contract with experienced interventionists and/or to invest in training psychiatric rehabilitation staff to conduct appropriate intervention components.

The ACHIEVE Trial tests an evidence-based approach to the problem of obesity in persons with serious mental illness. The study will provide knowledge about how to accomplish weight loss through an appropriately tailored intervention delivered in a psychiatric rehabilitation setting. Furthermore, the results from this study will inform future work in healthy lifestyle interventions for cardiovascular disease prevention in populations with chronic mental illness.

\section{Abbreviations \\ CES-D: refers to Center for Epidemiologic Studies Depression Scale; SF-12: refers to Short Form 12 Health Survey; HIPAA: refers to Health Insurance Portability and Accountability Act; GEE: refers to Generalized estimating equation.}

\section{Acknowledgements}

Funding for this study is provided by the National Institute of Mental Health, Grant R01MH080964

\section{Author details}

${ }^{1}$ Welch Center for Prevention, Epidemiology, and Clinical Research, Johns Hopkins University, Baltimore, Maryland, USA. 'Department of Medicine, Johns Hopkins University School of Medicine, Baltimore, Maryland, USA. ${ }^{3}$ Department of Kinesiology, Towson University, Towson, Maryland, USA ${ }^{4}$ Sheppard Pratt Health System, Towson, Maryland, USA. ${ }^{5}$ Department of Epidemiology, Johns Hopkins Bloomberg School of Public Health, Baltimore,
Maryland, USA. ${ }^{6}$ Department of Health Policy and Management, Johns Hopkins Bloomberg School of Public Health, Baltimore, Maryland, USA. VA Capitol Health Care Network (VISN 5) Mental IIIness, Research, Education and Clinical Center, Baltimore, Maryland, USA. ${ }^{8}$ Department of Psychiatry, University of Maryland School of Medicine, Baltimore, Maryland, USA. ${ }^{9}$ Department of Epidemiology and Biostatistics, University of Maryland School of Public Health, College Park, Maryland, USA. ${ }^{10}$ Department of Psychiatry, Johns Hopkins University School of Medicine, Baltimore, Maryland, USA. ${ }^{11}$ Department of Mental Health, Johns Hopkins Bloomberg School of Public Health, Baltimore, Maryland, USA.

\section{Authors' contributions}

GLD conceived the design of the study. EG and NYW participated in the analytic and statistical analysis plans. KDF participated in the cost-analysis plans. GJJ participated in developing the exercise intervention and bike test measures. FBD participated in the study design. CAA, JVG, SSS, AD participated in the design and implementation of the environmental nutrition intervention. RWG participated in the intervention design. JF designed the data entry and documentation system. MO led the intervention staff. OF and LC directed data collection. JBC participated in the coordination of the trial. SSC, GLD, and LJA drafted the article. All authors edited and approved the final manuscript.

\section{Competing interests}

The authors declare that they have no competing interests.

Received: 28 July 2010 Accepted: 13 December 2010 Published: 13 December 2010

\section{References}

1. Mokdad AH, Bowman BA, Ford ES, Vinicor F, Marks JS, Koplan JP: The continuing epidemics of obesity and diabetes in the United States. JAMA 2001, 286:1195-200.

2. Flegal KM, Carroll MD, Ogden CL, Curtin LR: Prevalence and trends in obesity among US adults, 1999-2008. JAMA 303:235-41.

3. Allison DB, Mentore JL, Heo M, Chandler LP, Cappelleri JC, Infante MC, Weiden PJ: Antipsychotic-induced weight gain: a comprehensive research synthesis. Am J Psychiatry 1999, 156:1686-96.

4. Coodin S: Body mass index in persons with schizophrenia. Can J Psychiatry 2001, 46:549-55.

5. Daumit GL, Clark JM, Steinwachs DM, Graham CM, Lehman A, Ford DE: Prevalence and correlates of obesity in a community sample of individuals with severe and persistent mental illness. J Nerv Ment Dis 2003, 191:799-805.

6. Hubert HB, Feinleib M, McNamara PM, Castelli WP: Obesity as an independent risk factor for cardiovascular disease: a 26-year follow-up of participants in the Framingham Heart Study. Circulation 1983, 67:968-77.

7. Pi-Sunyer FX: Medical hazards of obesity. Ann Intern Med 1993, 119:655-60.

8. Depression Guideline Panel: In Depression in Primary Care. Volume 2. Rockville, MD: AHCPR; 1993.

9. Macritchie KAN, Geddes JR, Scott J, Haslam DRS, Goodwin GM: Valproic acid, valproate and divalproex in the maintenance treatment of bipolar disorder (Cochrane Review). The Cochrane Library; 2002.

10. Physical Activity and Health: A Report of the Surgeon General. Atlanta: U.S. Department of Health and Human Services, Centers for Disease Control and Prevention National Center for Chronic Disease Prevention and Health Promotion 1996, 1-300.

11. The sixth report of the Joint National Committee on prevention, detection, evaluation, and treatment of high blood pressure. Arch Intern Med 1997, 157:2413-46.

12. Katz D, Oconnell M, Yeh M-C, Nawaz H, Njike V, Anderson L, Cory S, Deitz W: Public Health Strategies for Preventing and Controlling Overweight and Obesity in School Worksite Settings. A report on Recommendation of the Task Force on Community Preventive Services. 2005, 1-16.

13. Satcher D: The Surgeon General's call to action to prevent and decrease overweight and obesity. 2001, 1-39.

14. Allison DB, Newcomer JW, Dunn AL, Blumenthal JA, Fabricatore AN, Daumit GL, Cope MB, Riley WT, Vreeland B, Hibbeln JR, Alpert JE: Obesity 
Among Those with Mental Disorders: A National Institute of Mental Health Meeting Report. Am J Prev Med 2009, 36:341-350.

15. Appel L, Espeland MA, Easter L, Wilson AC, Folmar S, Lacy CR: Effects of reduced sodium intake on hypertension control in older individuals: results from the Trial of Nonpharmacologic Interventions in the Elderly (TONE). Arch Intern Med 2001, 161:685-93.

16. Elmer PJ, Obarzanek E, Vollmer WM, Simons-Morton D, Stevens VJ, Young DR, Lin PH, Champagne C, Harsha DW, Svetkey LP, Ard J, Brantley PJ, Proschan MA, Erlinger TP, Appel $\mathrm{L}$ : Effects of comprehensive lifestyle modification on diet, weight, physical fitness, and blood pressure control: 18-month results of a randomized trial. Ann Intern Med 2006, 144:485-95.

17. Faulkner $\mathrm{G}$, Cohn $\mathrm{T}$, Remington $\mathrm{G}$ : Interventions to reduce weight gain in schizophrenia. Cochrane Database Syst Rev 2007, CD005148.

18. Stevens VJ, Obarzanek E, Cook NR, Lee IM, Appel LJ, Smith West D, Milas NC, Mattfeldt-Beman M, Belden L, Bragg C, Millstone M, Raczynski J, Brewer A, Singh B, Cohen J: Long-term weight loss and changes in blood pressure: results of the Trials of Hypertension Prevention, phase II. Ann Intern Med 2001, 134:1-11.

19. Svetkey LP, Harsha DW, Vollmer WM, Stevens VJ, Obarzanek E, Elmer PJ, Lin PH, Champagne C, Simons-Morton DG, Aickin M, Proschan MA, Appel LJ: PREMIER: A Clinical Trial of Comprehensive Lifestyle Modification for Blood Pressure Control: Rationale, Design and Baseline Characteristics. Annals of Epidemiology 2003, 13:1-10.

20. Mueser KT, McGurk SR: Schizophrenia. Lancet 2004, 363:2063-72.

21. Ball MP, Coons VB, Buchanan RW: A program for treating olanzapinerelated weight gain. Psychiatr Serv 2001, 52:967-9.

22. Kalarchian MA, Marcus MD, Levine MD, Haas GL, Greeno CG, Weissfeld LA, Qin L: Behavioral treatment of obesity in patients taking antipsychotic medications. J Clin Psychiatry 2005, 66:1058-63.

23. Kwon JS, Choi JS, Bahk WM, Yoon Kim C, Hyung Kim C, Chul Shin Y, Park BJ, Geun Oh C: Weight management program for treatmentemergent weight gain in olanzapine-treated patients with schizophrenia or schizoaffective disorder: A 12-week randomized controlled clinical trial. J Clin Psychiatry 2006, 67:547-53.

24. Menza M, Vreeland B, Minsky S, Gara M, Radler DR, Sakowitz M: Managing atypical antipsychotic-associated weight gain: 12-month data on a multimodal weight control program. J Clin Psychiatry 2004, 65:471-7.

25. Pendlebury J, Haddad P, Dursun S: Evaluation of a behavioural weight management programme for patients with severe mental illness: 3 year results. Hum Psychopharmacol 2005, 20:447-8.

26. Vreeland B, Minsky S, Menza M, Rigassio Radler D, Roemheld-Hamm B, Stern R: A program for managing weight gain associated with atypical antipsychotics. Psychiatr Serv 2003, 54:1155-7.

27. Weber $M$, Wyne K: A cognitive/behavioral group intervention for weight loss in patients treated with atypical antipsychotics. Schizophr Res 2006, 83:95-101

28. McKibbin CL, Patterson TL, Norman G, Patrick K, Jin H, Roesch S, Mudaliar S, Barrio C, O'Hanlon K, Griver K, Sirkin A, Jeste DV: A lifestyle intervention for older schizophrenia patients with diabetes mellitus: a randomized controlled trial. Schizophr Res 2006, 86:36-44.

29. Rose G, McCartney P, Reid DD: Self-administration of a questionnaire on chest pain and intermittent claudication. Br J Prev Soc Med 1977, 31(1):42-48.

30. Cacciola JS, Alterman Al, McLellan AT, Lin YT, Lynch KG: Initial evidence for the reliability and validity of a "Lite" version of the Addiction Severity Index. Drug Alcohol Depend 2007, 87:297-302.

31. Moher D, Schulz KF, Altman DG: The CONSORT statement: revised recommendations for improving the quality of reports of parallel-group randomised trials. Clin Oral Investig 2003, 7:2-7.

32. Wadden TA, Berkowitz RI, Womble LG, Sarwer DB, Phelan S, Cato RK, Hesson LA, Osei SY, Kaplan R, Stunkard AJ: Randomized trial of lifestyle modification and pharmacotherapy for obesity. N Engl J Med 2005, 353:2111-20.

33. Bandura A: Social Foundations of thought and action: a social cognitive theory.Edited by: Hall P. Social Learning Theory Englewood Cliffs; 1986:617.

34. Marlatt GA, Gordon JR: Relapse Prevention: Maintenance Strategies in the treatment of addictive behaviors. Guilford clinical psychology and psychotherapy series. New York: Guildord Press; 1985, 558.
35. Prochaska JO, DiClemente CC: Stages and processes of self-change of smoking: toward an integrative model of change. J Consult Clin Psychol 1983, 51:390-5

36. Watson DL, Tharp RG: Self-directed behavior: Self-modification for personal adjustment. Monterey: Brooks/Cole Publishing Company; 1989

37. International classification of functioning, disability and health: ICF. World Health Organization: Geneva; 2001.

38. Brandt EN, Pope AM: Enabling America: assessing the role of rehabilitation science and engineering. Washington, DC: National Academy Press; 1997.

39. Appel L, Champagne C, Harsha D, Cooper LS, Obarzanek E, Elmer PJ, Stevens VJ, Vollmer WM, Lin PH, Svetkey LP, Stedman SW, Young DR: Effects of Comprehensive Lifestyle Modification on Blood Pressure Control: Main results of the PREMIER Clinical Trial. In JAMA. Volume 289. Writing Group of the PREMIER Collaborative Research Group; 2003:2083-2093.

40. Anthony WA, Rogers ES, Cohen M, Davies RR: Relationships between psychiatric symptomatology, work skills, and future vocational performance. Psychiatr Serv 1995, 46:353-8.

41. Green MF, Nuechterlein KH: Should schizophrenia be treated as a neurocognitive disorder? Schizophr Bull 1999, 25:309-19.

42. Bellack AS, Bennett ME, Gearson JS: Behavioral Treatment for Substance Abuse Treatment in Schizophrenia (BTSAS). Baltimore: University of Maryland School of Medicine; 2001, 1-197.

43. Velligan DI, Bow-Thomas CC, Huntzinger C, Ritch J, Ledbetter N, Prihoda TJ, Miller AL: Randomized controlled trial of the use of compensatory strategies to enhance adaptive functioning in outpatients with schizophrenia. Am J Psychiatry 2000, 157:1317-23.

44. Bellack AS: Psychosocial Behavior.Edited by: Tasman A, Kay J, Lieberman JA. Psychiatry London: Wiley; 2003:

45. American Heart Association and National Heart L, and Blood Institute: Exercise and Your Heart: A guide to physical activity. AHA 2001

46. McCullough ML, Karanja NM, Lin PH, Obarzanek E, Phillips KM, Laws RL, Vollmer WM, O'Connor EA, Champagne CM, Windhauser MM: Comparison of 4 nutrient databases with chemical composition data from the Dietary Approaches to Stop Hypertension trial. In J Am Diet Assoc. Volume 99. DASH Collaborative Research Group; 1999:S45-53.

47. Piantadosi S: Clinical Trials: A Methodologic Perspective. Baltimore, MD: Wiley Interscience; 2005.

48. Zeger SL, Liang KY: Longitudinal data analysis for discrete and continuous outcomes. Biometrics 1986, 42:121-30.

49. Stamler R, Stamler J, Gosch FC, Civinelli J, Fishman J, McKeever P, McDonald A, Dyer AR: Primary prevention of hypertension by nutritionalhygienic means. Final report of a randomized, controlled trial. JAMA 1989, 262:1801-7.

50. Fishman G: Monte Carlo: Concepts, Algorithms, and Applications. Springer: New Yorker; 1996.

51. Faulkner G, Cohn T, Remington G: Interventions to reduce weight gain in schizophrenia. Cochrane Database Syst Rev 2007, , 1: CD005148.

52. Daumit GL, Dalcin AT, Jerome GJ, Young DR, Charleston J, Crum RM, Anthony C, Hayes JH, McCarron PB, Khaykin E, Appel L: A behavioral weight loss intervention for persons with serious mental illness in psychiatric rehabilitation centers. Int J Obes 2010.

53. Whelton PK, Appel L, Espeland MA, Applegate WB, Ettinger WH Jr, Kostis JB, Kumanyika S, Lacy CR, Johnson KC, Folmar S, Cutler JA: Sodium reduction and weight loss in the treatment of hypertension in older persons: a randomized controlled trial of nonpharmacologic interventions in the elderly (TONE). In JAMA. Volume 279. TONE Collaborative Research Group; 1998:839-46.

54. Wadden TA, West DS, Neiberg RH, Wing RR, Ryan DH, Johnson KC, Foreyt JP, Hill JO, Trence DL, Vitolins MZ: One-year weight losses in the Look AHEAD study: factors associated with success. Obesity (Silver Spring) 2009, 17:713-22.

55. Hollis JF, Gullion CM, Stevens VJ, Brantley PJ, Appel LJ, Ard JD, Champagne CM, Dalcin A, Erlinger TP, Funk K, Laferriere D, Lin PH, Loria CM, Samuel-Hodge C, Vollmer WM, Svetkey LP: Weight loss during the intensive intervention phase of the weight-loss maintenance trial. Am J Prev Med 2008, 35:118-26.

56. Melamed Y, Stein-Reisner O, Gelkopf M, Levi G, Sivan T, Illevici G, Rosenberg R, Weizman A, Bleich A: Multi-modal weight control 
intervention for people with persistent mental disorders. Psychiatr Rehabil J 2008, 31(3):194-200.

57. Block G, Gillespie C, Rosenbaum EH, Jenson C: A rapid food screener to assess fat and fruit and vegetable intake. Am J Prev Med 2007, 18(4):284-8.

58. Block G, Clifford C, Naughton MD, Henderson M, McAdams M: A brief dietary screen for high fat intake. Journal of Nutrition Education 1989, 21(5):199-207.

59. Craig $C L$, Marshall $A L$, Sjostrom $M$, Bauman $A E$, Booth $M L$, Pratt $M$, Ekelund U, Yngve A, Sallis JF, Oja P: International physical activity questionnaire: 12-country reliability and validity. Med Sci Sports Exerc 2003, 35(8):1381-95.

60. Eisen SV, Normand SL, Belanger AJ, Spiro A, Esch D: The Revised Behavior and Symptom Identification Scale (BASIS-R): reliability and validity. Med Care 2004, 42(12):1230-41.

61. Weissman MM, Sholomskas D, Pottenger M, Prusoff BA, Locke BZ: Assessing depression symptoms in 5 psychiatric populations: a validation study. Am J Epidemiol 1977, 106(3):203-14.

62. Salyers MP, Bosworth HB, Swanson JW, Lamb-Pagone J, Osher FC Reliability and validity of the SF-12 health survey among people with severe mental illness. Med Care 2000, 38(11):1141-50.

63. Fryback DG, Dunham NC, Palta M, Hanmer J, Buechner J, Cherepanov D, Herrington SA, Hays RD, Kaplan RM, Ganiats TG, Feeny D, Kind P: US norms for six generic health-related quality-of-life indexes from the National Health Measurement study. Med Care 2007, 45(12):1162-70.

64. Kolotkin RL, Crosby RD, Corey-Lisle PK, Li H, Swanson JM: Performance of a weight-related measure of Quality of Life in a psychiatric sample. Qual Life Res 2006, 15(4):587-96.

65. Sherbourne CD, Stewart AL: The MOS social support survey. Soc Sci Med 1991, 32(6):705-14

66. Sallis JF, Grossman RM, Pinski RB, Patterson TL, Nader PR: The development of scales to measure social support for diet and exercise behaviors. Prev Med 1987, 16(6):825-836.

67. Schwarzer R: Measurement of Perceived Self-Efficacy: Psychometric Scales for cross-cultural research. Berlin: Berlin, Forschung and der Freien Universitat 1993.

68. Clark MM, Abrams DB, Niaura RS, Eaton CA, Rossi JS: Self-efficacy in weight management. J Consult Clin Psychol 1991, 59(5):739-44.

69. McAuley $\mathrm{E}$ : The role of efficacy cognitions in the prediction of exercise behavior in middle-aged adults. J Behav Med 1992, 15:65-88.

70. Spitzer RL, Devlin M, Walsh BT, Hasin D, Wing R, Marcus M, Stunkard A, Wadden T, Yanovski S, Agras S, Mitchell J, Nonas C: Binge eating disorder: A multisite field trial of the diagnostic criteria. International Journal of Eating Disorders 1992, 11:191-203.

71. Mujahid MS, Diez Roux AV, Morenoff JD, Raghunathan T: Assessing the measurement properties of neighborhood scales: from psychometrics to ecometrics. Am J Epidemiol 2007, 165(8):858-67.

72. Stalvey BT, Owsley C, Sloane ME, Ball K: The Life Space Questionnaire: A Measure of the Extent of Mobility of Older Adults. Journal of Applied Gerontology 1999, 18(4):460-78.

73. Buysse DJ, Reynolds CF, Monk TH, Berman SR, Kupfer DJ: The Pittsburgh Sleep Quality Index: a new instrument for psychiatric practice and research. Psychiatry Res 1989, 28(2):193-213.

\section{Pre-publication history}

The pre-publication history for this paper can be accessed here: http://www.biomedcentral.com/1471-244X/10/108/prepub

doi:10.1186/1471-244X-10-108

Cite this article as: Casagrande et al:: Randomized trial of achieving healthy lifestyles in psychiatric rehabilitation: the ACHIEVE trial. BMC Psychiatry 2010 10:108.

\section{Submit your next manuscript to BioMed Central and take full advantage of:}

- Convenient online submission

- Thorough peer review

- No space constraints or color figure charges

- Immediate publication on acceptance

- Inclusion in PubMed, CAS, Scopus and Google Scholar

- Research which is freely available for redistribution

Submit your manuscript at www.biomedcentral.com/submit
C) Biomed Central 